\title{
Trends of antimicrobial resistance in Escherichia coli isolates from urine cultures of women in Jordan: A 10-year retrospective study
}

\section{Abstract}

Background: Urinary tract infection (UTI) is a common medical condition among women. $E$. coli is the most common causative organism. Appropriate understanding of the development of antimicrobial resistance over the past helps to establish efficient treatment strategies in the future. The study aims to determine the antimicrobial resistance trends exhibited by $E$. coli isolates from women urine cultures over the past 10 years.

Methods: A total of 1874 positive urine samples over the years 2009 to 2018 were reviewed and classified according to the response to 24 different antimicrobial drugs in the laboratory. Relations between time and resistance evolutionary profiles were calculated.

Results: Gentamicin ( $p$ value $=0.039$ ), amoxicillin $(p$ value $=0.017$ ), cefoxitin ( $p$ value $=0.001$ ) and cefixime ( $p$ value $=0.026$ ) fulfilled satisfactory figures in terms of average resistance, regression of resistance, speed of resistance evolution, steadiness of performance, side effects, spectrum range and cost with high significance.

Conclusion: Antibiotics that showed satisfactory susceptibility in culture are recommended for future treatment protocols of urinary tract infection in Jordan.

\section{Keywords}

Antimicrobial Resistance; E. coli resistance; Urinary Tract Infection; Women; Jordan.

Mustafa Alrabayah', Nisreen Nadi², Aiman Suleiman², Ala' Abbad', Hadil Ghanem², Ahmad Obeidat ${ }^{2}$, Maysarah Alaqrabawi², Mohammad Yousef?', Taima'a Harb², Isam Bsisu²

1 Assistant professor at The University of Jordan School of Medicine/Amman.

2 Anesthesia and Intensive Care,The Jordan University Hospital/Amman, Jordan.

\section{Contact information:}

\section{Dr. Nisreen Abdel-Kareem Nadi.}

Address: School of Medicine, The University of Jordan. PO Box 13046, Amman, 11942, Jordan.

$\equiv$ nisreen.nadi@ymail.com 


\section{Introduction}

Antimicrobial resistance is a mounting threat to human societies [1]. Understanding the patterns of resistant traits evolution and regression according to the change in the treatment protocols and antimicrobial usage gives strong predictions of how the resistance course will change over time, which helps in reformulating future strategies that could slow the progression of resistance.

Escherichia coli is one of the most commonly opportunistic bacteria associated with humans today [2]. When E. coli is exposed to antibiotics, their cells developing resistant traits to survive and reproduce rapidly [3]. Prolonged exposure to antibiotics increases the activity of specific regulatory proteins that work on gene segments leading to the extrusion of antimicrobials out of the bacterial cell before reaching their target organelles [3]. The fastest way for bacteria to acquire resistance is through cell horizontal transfer of genetic structures called plasmids that contain specific DNA segments [4]. Plasmids can spread through an entire community of bacterial population within about 30 minutes [4]. They are capable of sharing genetic segments for specific efflux pumps that work on the cell wall of the bacteria to extrude antimicrobial molecules [5]. Bacteria can lose their acquired resistance if the selective pressure applied is changed or eliminated but this biological process occurs more slowly [6].

Urinary tract infections (UTI) due to E. coli occurs mostly in the lower parts of urinary system, the bladder and the urethra, causing cystitis and urethritis respectively. At times, it can be transferred to the kidneys causing pyelonephritis [7]. Women have much higher chance of acquiring UTI than men because they have a shorter urethra, since $E$. coli is heavily present in fecal matter, and can easily be transferred to the urethra through the urethral opening [8]. Infection can occur by sexual contact [9], improper wiping techniques after defecation; wiping from back to front [9] and holding of urine; frequent urination allows flushing of $E$. coli and decreases the risk of infection [10]. Many other direct causes of infection can be present, like having a urinary catheter, using birth control methods or taking regular courses of antibiotics [11].

A total of $1-3 \%$ of all medical consultations in Great Britain compromises UTIs [12]. E. coli, on average is responsible for nearly $85 \%$ of UTI infections [13]. The average annual UTIs is 150 million cases globally [11]. Although the average is rising in both sexes, the increase rate in women is twice as men [14]. A total of $60 \%$ of women worldwide are estimated to develop UTI at least once in their lifetime [15]. Recent studies in Jordan, reported increased antibiotics resistance among E. coli uropathogens [16].

The aim of this study is to present a useful informative data for future establishment of antimicrobial usage in Jordan. To the best of our knowledge, this is the first study in Jordan to incorporate data of UTI in women into establishing local protocols for antibiotic usage.

\section{Method and Materials}

\section{Study design}

This study was conducted at The Jordan University Hospital (JUH), a tertiary hospital in Amman, Jordan. It gained acceptance by the Institutional Review Board (IRB No.10/2019/25180). Our inclusion criteria consisted of nonpregnant women who regularly visited JUH and were covered by the hospital insurance system. This is to ensure that patients followed unified treatment protocols and strategies and the bacterial urine cultures were subjected to the same laboratory conditions over the 10 years period. Men were excluded due to anatomical variables and different aetiologias and treatment protocols. Other body fluid cultures were excluded due to different treatment strategies. Table 1 shows 
Vol. 10 No. $3: 2$ doi: $10.3823 / 849$
Table 1. Antimicrobial drugs arranged according to their market availability in Jordan and current role for UTI treatment.

\begin{tabular}{|c|c|c|}
\hline Antibiotic & $\begin{array}{c}\text { Market } \\
\text { availability } \\
\text { years [17] }\end{array}$ & $\begin{array}{l}\text { Current role in treatment } \\
\text { protocols [18] }\end{array}$ \\
\hline Amikacin & $2009-2018$ & Resistant ESBL infections \\
\hline Amoxicillin & 2009-2018 & $\begin{array}{c}\text { First line agent in UTI in } \\
\text { pregnancy }\end{array}$ \\
\hline Ampicillin & 2012-2018 & First line agent in pregnancy \\
\hline Cefepime & $2009-2012$ & No current role \\
\hline Cefixime & $2015-2018$ & No current role \\
\hline Cefotaxime & 2011-2018 & No current role \\
\hline Cefoxitin & 2017-2018 & Second line agent for cystitis \\
\hline Cefpodoxime & N/A & No current role \\
\hline Ceftazidime & N/A & No current role \\
\hline Ceftriaxone & $2009-2018$ & $\begin{array}{c}\text { First line agent in severely ill } \\
\text { patients, Third line agent in } \\
\text { pyelonephritis }\end{array}$ \\
\hline Cefuroxime & 2009-2018 & Second line agent for cystitis \\
\hline Cephalothin & N/A & $\begin{array}{l}\text { Second line agent for cystitis } \\
\text { and UTI in pregnancy }\end{array}$ \\
\hline Ciprofloxacin & 2009-2018 & $\begin{array}{l}\text { Second line agent for } \\
\text { pyelonephritis }\end{array}$ \\
\hline Cotrimoxazole & $2011-2018$ & $\begin{array}{c}\text { First line agent for cystitis and } \\
\text { pyelonephritis }\end{array}$ \\
\hline Ertapenem & $2010-2018$ & $\begin{array}{l}\text { Severe, complicated and } \\
\text { resistant pyelonephritis, ESBL } \\
\text { infection }\end{array}$ \\
\hline Gentamicin & 2009-2018 & $\begin{array}{l}\text { Second line agent in severely } \\
\text { ill patients }\end{array}$ \\
\hline Imipenem & 2009-2018 & $\begin{array}{l}\text { Severe, complicated and } \\
\text { resistant pyelonephritis, ESBL } \\
\text { infection }\end{array}$ \\
\hline Meropenem & 2009-2018 & No current role \\
\hline Nalidixic acid & N/A & No current role \\
\hline Nitrofurantoin & $2009-2016$ & $\begin{array}{l}\text { First line agent for cystitis and } \\
\text { UTI in pregnancy }\end{array}$ \\
\hline Norfloxacin & N/A & No current role \\
\hline $\begin{array}{l}\text { Piperacillin / } \\
\text { tazobactam }\end{array}$ & 2014-2018 & $\begin{array}{l}\text { Severe, complicated and } \\
\text { resistant infections }\end{array}$ \\
\hline Tetracycline & 2009-2018 & No current role \\
\hline Tobramycin & 2009-2018 & No current role \\
\hline
\end{tabular}

the list of enrolled 24 antibiotics, the sample size for each antibiotic, the years of market availability in Jordan and the current role in UTI treatment protocols.

\section{Data collection and analysis}

Retrospective collection of 1874 urine sample results from January 2009 to December 2018 was done. Culture and sensitivity reports were obtained from the records of Microbiology Department at The $J U H$. Response of $E$. coli to 24 different antibiotics was categorized to susceptible (S) or resistant (R). Susceptibility or resistance to extended spectrum $\beta$ lactamase (ESBL) results were interpreted according to the Clinical Laboratory Standard Institute (CLSI) 2017 protocols [19]. ESBL percentages were calculated since the start of conducting the test (May, 2017 to December, 2018).

Data was analyzed by SPSS version 23 program and presented by Microsoft Excel program, office 2019. Descriptive statistics and frequencies were applied. Moreover, linear regression analysis was done to investigate the change in resistance over ten years and Pearson's $r$ was calculated. P-value < 0.05 was considered to indicate statistically significant difference.

\section{Interpretation}

Results interpretation took accredited international and national antimicrobial resistance recommendations into consideration. Antimicrobial market drug availability and usage during the 10-year period was also considered. Final recommendations for future treatment protocols were constructed using rationale of antimicrobial stewardship strategy formulary restrictions accredited by Ontario public health [20]. North York general antimicrobial restriction guidelines (accredited in 2015) are applied in JUH and were also taken into consideration [21]. 


\section{Results}

The mean age of patients was $37.1 \pm 14.6$ years. Median age was 32 years. Among 26537 collected urine samples, 9970 (37.6\%) samples showed bacterial growth. After exclusion of mixed growth samples. Out of 4164 samples were left, 1874 sam- ples showed E. coli growth (45\%). Annual results of sensitivity and resistance to each antibiotic are shown in Table 2.

Analysis of data collected showed that 10 out of 24 antibiotics have P-values of less than 0.05 as shown in Table 3. Out of these ten antibiotics, the highest average resistance rate was to amoxicillin (68.5\%; P-value=0.017) followed by cefotaxime and ceftriaxone with average resistance rates of $(65.9 \%$ and $65.7 \%$, respectively) and P-value of 0.004 and 0.452 , respectively, while the average resistance rate to gentamicin was (22.1\%; P-value $=0.039$ ).

Table 2. The percentage of antimicrobial resistant $E$. coli isolates among the total number of samples per year.

\begin{tabular}{|c|c|c|c|c|c|c|c|c|c|c|c|c|c|c|c|c|c|c|c|c|}
\hline \multirow{2}{*}{ Year } & \multicolumn{2}{|c|}{2009} & \multicolumn{2}{|c|}{2010} & \multicolumn{2}{|c|}{2011} & \multicolumn{2}{|c|}{2012} & \multicolumn{2}{|c|}{2013} & \multicolumn{2}{|c|}{2014} & \multicolumn{2}{|c|}{2015} & \multicolumn{2}{|c|}{2016} & \multicolumn{2}{|c|}{2017} & \multicolumn{2}{|c|}{2018} \\
\hline & $n$ & $r \%$ & $n$ & $r \%$ & $n$ & $r \%$ & $n$ & $r \%$ & $n$ & $r \%$ & $n$ & $r \%$ & $n$ & $r \%$ & $n$ & $r \%$ & $n$ & $r \%$ & $n$ & $r \%$ \\
\hline Amikacin & 13 & 7.69 & 19 & 21.05 & 22 & 9.09 & 55 & 38.18 & 70 & 5.71 & 212 & 8.49 & 162 & 14.81 & 160 & 14.38 & 103 & 4.85 & 18 & 27.78 \\
\hline Amoxicillin & 89 & 75.28 & 123 & 70.73 & 157 & 82.80 & 142 & 82.39 & 158 & 75.32 & 264 & 81.82 & 239 & 69.87 & 219 & 69.41 & 237 & 45.15 & 246 & 32.11 \\
\hline Ampicillin & - & - & - & - & - & - & - & - & - & - & - & - & - & - & - & - & 136 & 78.68 & 221 & 71.04 \\
\hline Cefepime & - & - & - & - & - & - & - & - & - & - & - & - & - & - & - & - & 135 & 72.59 & 221 & 64.25 \\
\hline Cefixime & 13 & 53.85 & 19 & 68.42 & 22 & 77.27 & 55 & 69.09 & 70 & 68.57 & 212 & 49.06 & 162 & 41.98 & 160 & 44.38 & 103 & 30.10 & 18 & 27.78 \\
\hline Cefotaxime & 88 & 43.18 & 123 & 35.77 & 157 & 42.04 & 142 & 38.03 & 158 & 44.94 & 264 & 50.38 & 239 & 43.51 & 219 & 52.05 & 101 & 46.53 & 31 & 48.39 \\
\hline Cefoxitin & 13 & 69.23 & 19 & 89.47 & 22 & 100.00 & 55 & 72.73 & 71 & 78.87 & 211 & 54.03 & 161 & 54.04 & 160 & 59.38 & 235 & 40.43 & 244 & 40.57 \\
\hline Cefpodoxime & 13 & 30.77 & 19 & 31.58 & 22 & 31.82 & 55 & 25.45 & 71 & 23.94 & 211 & 20.85 & 161 & 13.04 & 160 & 24.38 & 235 & 16.17 & 242 & 11.98 \\
\hline Ceftazidime & - & - & - & - & - & - & - & - & - & - & - & - & - & - & - & - & 135 & 40.74 & 221 & 40.27 \\
\hline Ceftriaxone & 13 & 61.54 & 19 & 73.68 & 22 & 86.36 & 55 & 70.91 & 70 & 65.71 & 212 & 51.89 & 162 & 44.44 & 160 & 55.63 & 236 & 39.41 & 244 & 40.57 \\
\hline Cefuroxime & 13 & 69.23 & 19 & 89.47 & 22 & 100.00 & 55 & 72.73 & 70 & 78.57 & 212 & 54.72 & 162 & 54.94 & 160 & 61.88 & 103 & 37.86 & 21 & 38.10 \\
\hline Cephalothin & 88 & 44.32 & 123 & 38.21 & 157 & 45.22 & 142 & 50.70 & 158 & 50.00 & 264 & 57.58 & 239 & 44.35 & 219 & 53.42 & 234 & 45.73 & 244 & 44.26 \\
\hline Ciprofloxacin & 13 & 76.92 & 19 & 78.95 & 22 & 95.45 & 55 & 74.55 & 69 & 66.67 & 211 & 47.39 & 162 & 45.68 & 160 & 47.50 & 236 & 29.24 & 244 & 28.69 \\
\hline Cotrimoxazole & 89 & 57.30 & 123 & 60.98 & 157 & 61.15 & 142 & 59.86 & 158 & 54.43 & 264 & 60.98 & 239 & 54.81 & 219 & 62.10 & 237 & 53.59 & 245 & 46.12 \\
\hline Ertapenem & - & - & 9 & 22.22 & 19 & 10.53 & 55 & 0.00 & 70 & 1.43 & 212 & 2.36 & 162 & 2.47 & 160 & 0.63 & 103 & 0.97 & 18 & 5.56 \\
\hline Gentamicin & 89 & 25.84 & 124 & 27.42 & 157 & 26.75 & 142 & 19.01 & 158 & 17.09 & 264 & 26.89 & 239 & 20.50 & 219 & 21.46 & 236 & 19.49 & 246 & 16.26 \\
\hline Imipenem & 13 & 0.00 & 19 & 5.26 & 22 & 0.00 & 55 & 0.00 & 70 & 0.00 & 211 & 1.90 & 162 & 1.23 & 160 & 1.88 & 236 & 0.42 & 242 & 0.83 \\
\hline Meropenem & - & - & - & - & - & - & - & - & - & - & - & - & - & - & - & - & 136 & 0.00 & 222 & 0.45 \\
\hline
\end{tabular}




\begin{tabular}{|c|c|c|c|c|c|c|c|c|c|c|c|c|c|c|c|c|c|c|c|c|}
\hline \multirow{2}{*}{ Year } & \multicolumn{2}{|c|}{2009} & \multicolumn{2}{|c|}{2010} & \multicolumn{2}{|c|}{2011} & \multicolumn{2}{|c|}{2012} & \multicolumn{2}{|c|}{2013} & \multicolumn{2}{|c|}{2014} & \multicolumn{2}{|c|}{2015} & \multicolumn{2}{|c|}{2016} & \multicolumn{2}{|c|}{2017} & \multicolumn{2}{|c|}{2018} \\
\hline & $n$ & $r \%$ & $n$ & $r \%$ & $n$ & $r \%$ & $n$ & $r \%$ & $n$ & $r \%$ & $n$ & $r \%$ & $n$ & $r \%$ & $n$ & $r \%$ & $n$ & $r \%$ & $n$ & $r \%$ \\
\hline Nalidixic acid & 89 & 57.30 & 123 & 56.10 & 157 & 57.32 & 142 & 59.86 & 158 & 56.33 & 264 & 68.18 & 239 & 65.27 & 219 & 66.67 & 100 & 68.00 & 21 & 66.67 \\
\hline Nitrofurantoin & 89 & 3.37 & 123 & 2.44 & 157 & 8.92 & 142 & 23.94 & 158 & 32.91 & 264 & 39.77 & 239 & 17.99 & 219 & 33.79 & 237 & 24.47 & 246 & 17.07 \\
\hline Norfloxacin & 88 & 32.95 & 123 & 35.77 & 157 & 34.39 & 142 & 35.21 & 158 & 34.81 & 264 & 41.67 & 239 & 38.08 & 219 & 42.47 & 237 & 32.07 & 245 & 27.35 \\
\hline $\begin{array}{l}\text { Piperacillin / } \\
\text { tazobactam }\end{array}$ & - & - & - & - & - & - & - & - & - & - & - & - & - & - & - & - & 134 & 11.19 & 222 & 8.11 \\
\hline Tetracycline & - & - & - & - & - & - & - & - & - & - & - & - & - & - & - & - & 133 & 52.63 & 221 & 47.51 \\
\hline Tobramycin & - & - & - & - & - & - & - & - & - & - & - & - & - & - & - & - & 133 & 18.80 & 219 & 15.98 \\
\hline
\end{tabular}

$\mathrm{n}$ : Total sample numbers; $\mathrm{r} \%$ : Percent of resistant cases.

Table 3. The average antibiotic resistance of $E$. coli isolates, $\mathrm{P}$-value, Pearson's $r$, variance and trend for each antibiotic over the 10-year period.

\begin{tabular}{|c|c|c|c|c|c|c|c|c|c|c|c|}
\hline \multirow{2}{*}{ Antibiotic } & Average resistance & \multirow{2}{*}{ P value } & \multirow{2}{*}{ Pearson's r } & \multirow{2}{*}{ Variance } & \multirow{2}{*}{ Trend } & \multirow{2}{*}{ Antibiotic } & Average resistance & \multirow{2}{*}{$P$ value } & \multirow{2}{*}{ Pearson's r } & \multirow{2}{*}{ Variance } & \multirow{2}{*}{ Trend } \\
\hline & $\%$ & & & & & & $\%$ & & & & \\
\hline Amikacin & 15.20 & 0.902 & 0.045 & 0.011746 & + & Ertapenem & 5.10 & 0.094 & -0.59 & 0.005173 & - \\
\hline Amoxicillin* & 68.50 & 0.017 & -0.726 & 0.028271 & - & Gentamicin* & 22.10 & 0.039 & -0.656 & 0.001838 & - \\
\hline Ampicillin & 74.90 & - & - & - & & Imipenem & 1.20 & 0.722 & -0.129 & 0.000266 & - \\
\hline Cefepime** $^{*}$ & 53.00 & 0.004 & -0.814 & 0.030014 & - & Meropenem & 0.30 & - & - & - & \\
\hline Cefixime* $^{*}$ & 44.50 & 0.026 & 0.693 & 0.002643 & + & Nalidixic acid** & 62.20 & 0.002 & 0.855 & 0.002708 & + \\
\hline Cefotaxime** & 65.90 & 0.004 & -0.817 & 0.039546 & - & Nitrofurantoin & 20.50 & 0.095 & 0.556 & 0.016684 & + \\
\hline Cefoxitin** & 23.00 & 0.001 & -0.879 & 0.00547 & - & Norfloxacin & 35.50 & 0.816 & -0.085 & 0.001997 & - \\
\hline Cefpodoxime & 40.50 & - & - & - & & \multirow{2}{*}{$\begin{array}{l}\text { Piperacillin / } \\
\text { tazobactam }\end{array}$} & \multirow{2}{*}{9.70} & \multirow{2}{*}{-} & \multirow{2}{*}{-} & \multirow{2}{*}{-} & \\
\hline Ceftazidime** $^{* *}$ & 59.00 & 0.005 & -0.801 & 0.023945 & - & & & & & & \\
\hline Ceftriaxone** & 65.70 & 0.004 & -0.817 & 0.041746 & - & Tetracycline & 50.10 & - & - & - & \\
\hline Cefuroxime & 47.40 & 0.452 & 0.269 & 0.00309 & + & Tobramycin & 17.40 & - & - & - & \\
\hline Cephalothin & 68.40 & - & - & - & & \multirow{3}{*}{\multicolumn{6}{|c|}{$\begin{array}{r}\text { *: A significance of }<0.05 \text { is marked by , **: while if }<0.005, \text { it is marked by } \\
\text { on's } r \text {, variance and trend were not calculated for antimicrobial drugs that were } \\
\text { tested through a period of } \leq 2 \text { years. }\end{array}$}} \\
\hline Ciprofloxacin** & 59.10 & 0 & -0.916 & 0.051082 & - & & & & & & \\
\hline Cotrimoxazole & 57.10 & 0.083 & -0.574 & 0.002493 & - & & & & & & \\
\hline
\end{tabular}


Overall trends of antimicrobial resistance were noticed to be positive for five antibiotics (amikacin, nitrofurantoin, nalidixic acid, cefuroxime and cefixime) but negative for other twelve antibiotics (gentamicin, cotrimoxazole, ciprofloxacin, norfloxacin, amoxicillin, imipenem, ertapenem, cefoxitin, ceftazidime, cefotaxime, ceftriaxone and cefepime). Figure 1 shows trends of antimicrobial resistance in E. coli isolates for antibiotics with significant P-value of $<0.05$.

The remaining seven antibiotics (tobramycin, tetracycline, piperacillin / tazobactam, ampicillin, meropenem, cephalothin and cefpodoxime) were tested at The JUH laboratories for only two years

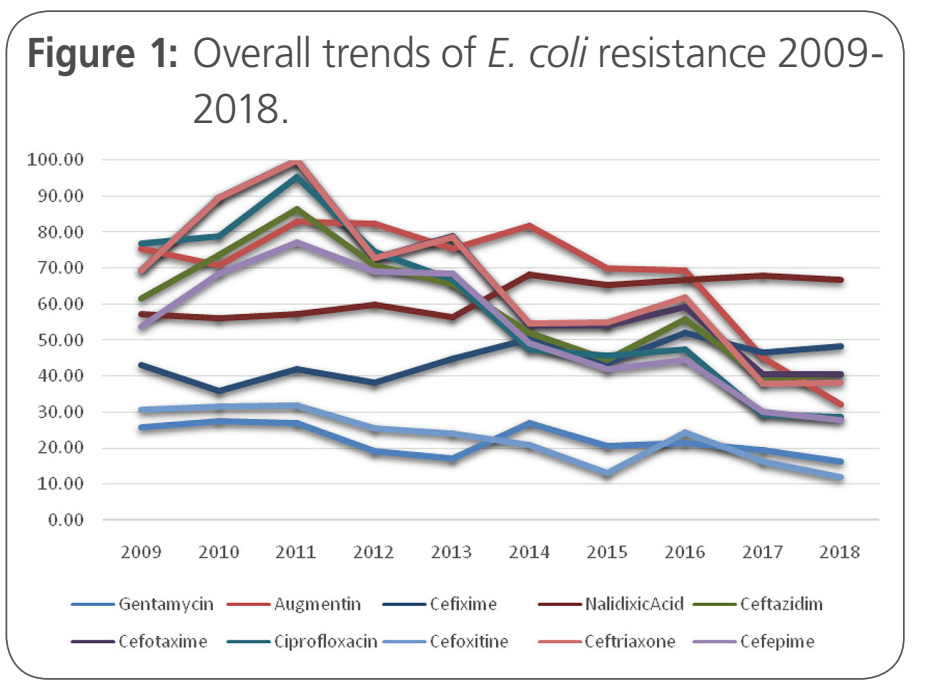

(2017-2018). Through this period, the average resistance to ampicillin was the highest among this group of antibiotics and among all 24 antibiotics too with average resistance rate of (74.9\%) while meropenem had the least average resistance rate $(0.3 \%)$.

ESBL positivity test was added by The JUH laboratory protocols in the period from May 2017 to December 2018. Results of positive and negative ESBL were calculated monthly. The average rate of positive ESBL strains of $E$. coli over 20 months was (33.1\%) and its overall trend was positive as shown in Figure 2.

\section{Discussion}

Many concerns have been rising due to the emergence of new bacterial strains that are resistant to multiple antibiotics which are considered as the first line of treatment in UTI. The most common among these strains is the ESBL producers, which has developed resistance against penicillins and tetracyclines [22]. ESBL adaptation still has not worked against carbapenems [22], whereas many other resistant strains of $E$. coli are rising in recent years. For example, UTIs caused by ciprofloxacin-resistant E. coli have increased from $3 \%$ to $17 \%$ between the years 2000 to 2010 [23], pushing up the importance

Figure 2: Percentages of ESBL in the period from May 2017 to December 2018.

\section{ESBL percentages}

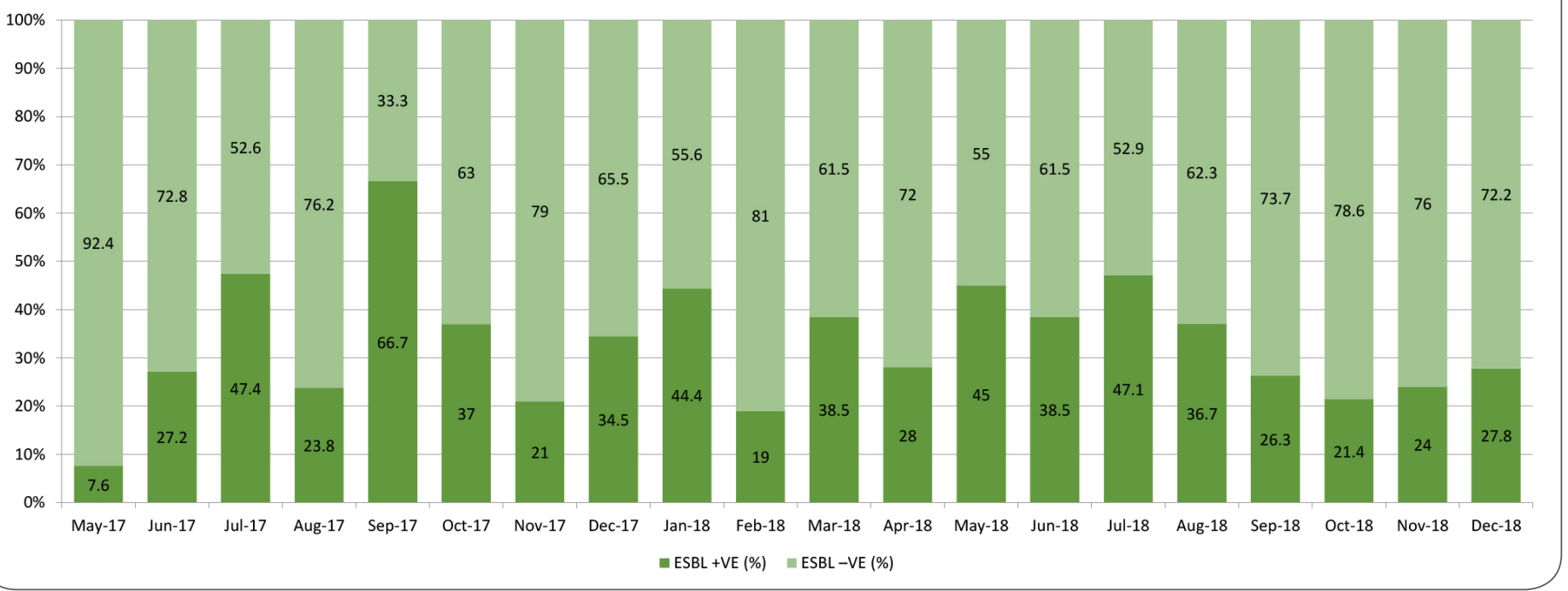


of understanding the patterns of resistance in this type of bacteria and the urge to counter it.

The accredited protocols for prescribing antibiotics in JUH are according to the recommendations of National Antimicrobial Resistance Plan [24], World Health Organization (WHO) Antimicrobial Resistance (AMR) Plan [25], Joint Commission International $(\mathrm{JCl})$ protocols of antimicrobial descriptions [26], and Pharmaceutical drugs description and awareness protocols of pharmacy department at The JUH [27]

In this study, we will discuss each antimicrobial class on an individual basis as follow:

\section{Amikacin}

It can be used as a therapeutic option for resistant ESBL E. coli isolates in case of limited resources [28]. Following accreditation of AMR plan in 2016, amikacin has shown minimal variance in resistance profiles.

\section{Gentamicin}

E. coli resistance to gentamicin can vary on institutional basis [29]. There is a slow trending down in resistance with overall low average resistance (22.1\%). Gentamicin is used as a second line agent in severely ill patients. AMR plans restricted the usage of gentamicin to severe infections; this approach may has helped in the low rate of resistance values following 2016.

\section{Tobramycin and tetracycline}

Both have no current role in UTI treatment guidelines [18], but this approach should follow further studies on their performances in the following years.

\section{Cotrimoxazole}

It has an overall negative trend and is used as a first line agent. Cotrimoxazole has shown steadiness in performance over many years even to other

E. coli infections [30]. Though it has a high average resistance (57.1\%), the application of good antimicrobial usage plans could control the resistance towards it as shown in the years following 2016.

\section{Nitrofurantoin}

It showed a great increase in resistance between the years of 2009 (3.4\%) to 2014 (39.8\%) followed by a period of slow regression in resistance since nitrofurantoin was unavailable in The JUH during the years 2015-2017. This fact may explaining the mild regression in resistance that took place in the following years. The overall trend of resistance is positive which emphasizes the revision of treatment protocols that consider nitrofurantoin as a first line agent. This antibiotic is also recommended for empiric therapy for community-acquired and nosocomial lower UTI caused by E. coli susceptible to it. Additionally, nitrofurantoin is also active against most strains of multidrug-resistant gram-negative bacilli including most ESBL-producing strains except Proteus spp. and Pseudomonas aeruginosa [31].

\section{Ciprofloxacin}

There is an evident increase in resistance in the period 2009 (76.9\%) to 2011 (95.5\%), then a near steady state took over in the years 2012 to 2016, followed by regression of resistance in the following years. Though the average resistance of ciprofloxacin remains high (59.1\%), and the overall trend of resistance is negative which makes ciprofloxacin a reliable antimicrobial choice. It is evident that a significant drop in resistance followed the accreditation of AMR plans in 2016. Ciprofloxacin is a good candidate for present and future strategies in treating UTIs caused by E. coli. Though its resistance has regressed. Rates of ciprofloxacin resistant of uropathogenic $E$. coli in this study and other Jordanian studies are much higher than many other studies worldwide [23]. A recent study carried out in Jordan has indicated alarming high rates recovery of multi-drug resistant uropathogenic E. coli from Jordanian patients associated with high rates of positive ST131 clone and fluoroquinolone resistant and important types of blaCTX-M [16]. Also, it has been shown that multi-drug resistant $E$. coli to 3 or 
more antibiotic classes causing urinary tract infections will be often associated with treatment failure, particularly in association with bacterial strains carrying $C T X-M$ extended spectrum $\beta$-lactamases [32]. In addition, it has been reported that CTX-M-15 extended spectrum $\beta$-lactamases encoding genes are widely spread among Enterobacteriaceae in the Middle Eastern region [33].

\section{Norfloxacin and Nalidixic acid}

Though both drugs have high average resistance (35.5\% and $62.2 \%$, respectively), the resistance rates showed steadiness towards them over the 10-year period. Both antibiotics were never used in treating UTIs caused by E. coli in The JUH. Nevertheless, Nalidixic acid resistance is rising. Norfloxacin showed favorable susceptibility results and is a good candidate for future treatment protocols.

\section{Amoxicillin}

A relatively steady resistance is shown between the years 2009-2016 with a great decline in resistance profile following 2016. This trend is probably in relation to the accreditation of AMR plans and the restrictions over amoxicillin use as over-the-counter drug. Though amoxicillin has a high average resistance (68.5\%), the inclusion of amoxicillin in future strategies in treating UTI depends on other factors as this antibiotic has minimal side effects and a rapid recovery profile, this is consistent with its traditional usage as oral treatment of UTI [34]. Amoxicillin resistance profile is a good example of reversing the resistance process rapidly when the selective pressure on the bacteria is eliminated.

\section{Piperacillin/tazobactam and ampicillin}

These antibiotics were added to the laboratory protocols in 2017. There were no significant changes in their resistance profiles over the following year with average resistance rates of $(9.7 \%$ and $74.9 \%)$ respectively. Previous Jordanian studies reported also the prevalence of high resistance rates of $E$. coli isolates to ampicillin over the last 10-year [16, 39].

\section{Imipenem, Ertapenem and Meropenem}

Overall, the averages of resistance for all carbapenems are low $(1.2 \%, 5.1 \%$ and $0.3 \%$, respectively). Imipenem showed a steady performance against $E$. coli, with a negative annual trend. The restrictions applied by infection control departments at The $\mathrm{JUH}$ on the usage of imipenem as an empirical antimicrobial treatment helped in the regression of imipenem-resistant E. coli seen in the years 2017 to 2018. Resistance towards ertapenem showed a significant decline over the years between 2010 to 2018 with a negative overall trend. A progression in resistance was noted following the application of the new protocols in 2016, which enforces the statement that more restrictions should be put on prescribing this antibiotic. Ertapenem resistance worldwide have shown a significant increase following the year 2015 [35]. Carbapenems should be always reserved as the last lines of treatment for severe life-threatening cases. We advice the need for prudent and rational use of carbapenems in our country.

\section{Cephalosporins}

ESBLs are most common in E. coli and K. pneumoniae. The most typical type of infection they cause is urinary tract infections. Also, they can cause other serious infections and are most likely to be resistant to many of the empirical antibiotics used for these infections [36]. Infections with ESBL-producers are most common amongst elderly people or those who have recently been in hospital and received antibiotic treatment. The incidence of these infections has been increasing worldwide including Jordan $[16,36]$. Therefore, minimizing the spread of resistant organisms relies in part on only using antibiotics when necessary and at appropriate doses and duration in both the community and hospitalized patients [37].

\section{First generation cephalosporins}

Cephalothin was used widely since mid seventy of the last century at The JUH and recently added to 
the laboratory protocols in 2017. Overall, it shows a high resistance profile with average resistance of $(68.4 \%)$.

\section{Second generation cephalosporins}

E. coli exhibited a steady resistance profile towards cefuroxime over the 10 years period with a minimal annual growth rate; hence, cefuroxime is still considered one of the effective antimicrobials in the treatment of UTIs caused by E. coli at The JUH. The resistance profile of cefuroxime showed minimal regression in resistance after applying AMR plans during 2016. The latest treatment strategies helped in decreasing the selective pressure applied by ciprofloxacin and ceftriaxone but led to increase usage of cefuroxime which in turn might lead to increased resistance towards it. A relatively high average resistance (47.4\%) that is trending up might enforce a revision of future treatment protocols that contain cefuroxime and encourage the switch to other drugs in the same class with lower resistance. Although with minimal variance and mild side effects, it is still counted as a recommended drug for any future strategies. E. coli exhibited regression of resistance towards cefoxitin, with negative overall trend of resistance, as the drug has not been available for usage in JUH since 2009. Recently in 2018, cefoxitin has replaced cefuroxime in many major departments in the hospital in a hope to reduce the resistance towards cefuroxime. Rates of resistance towards cefuroxime in this study seem to be less than worldwide reports [38]. In a former multicenter study conducted in Jordan, cefuroxime resistance rate was $61.7 \%$, notably, $21.2 \%$ were resistant to cefoxitin [39].

\section{Third generation cephalosporins}

An increase in resistance towards cefixime is noted (43.2\% to $48.4 \%)$ over the 10 -year. Though it was used in many treatment protocols, it showed minimal variance with near steady performance. According to low cost and mild side effects, cefixime might play a role in future treatment protocols. ceftazidime and cefotaxime were used in the years 2009-2012 in many treatment protocols at The JUH, hence, we can relate the rapid development of resistance seen in these two antibiotics in the years mentioned. But since 2012, ceftriaxone largely took over and replaced these two antibiotics in all major departments in the hospital. Ceftriaxone resistance evolution has a negative trend. Since 2016, there were major restrictions on the prescription of broad-spectrum antibiotics at The $\mathrm{JUH}$, including ceftriaxone with new strategies that encourage the use of cefuroxime in the treatment of UTI instead of ceftriaxone. This probably helped in regression of resistance towards ceftriaxone in the years 2016 to 2018. ESBL bacteria is the most common cause for ceftriaxone resistance [40].

\section{Fourth generation cephalosporins}

A significant regression in resistance towards cefepime is evident with a negative overall trend. Cefepime was never available for prescription at The JUH after 2009, explaining the significant regression of resistance towards this antibiotic. With a high average resistance (53.0\%) and variance, cefepime is not recommended in the near future protocols but might be one of our few weapons in the far future [41].

Due to the high prevalence of ESBL-positive isolates of $E$. coli in our region $[16,42]$. ESBL test for positivity was added to the laboratory protocols in May, 2017. Overall, there is a mild increase in the percentage of $E$. coli isolates that showed positivity for ESBL testing over a period of 20 months. Strict antimicrobial strategies and protocols helped in decreasing the development of ESBL positive traits.

According to the data analysis, E. coli has shown different degrees of resistance. Understanding the patterns of this evolutionary process, the speed of it and the variance of growth rates exhibited in relation to changing the treatment strategies determines the best drug to use when carrying out 
continuous analyses of bacterial cultures and their antibiotics susceptibility results.

\section{Recommendations}

Summarizes our recommendations, the antimicrobials labelled in $\mathrm{C}$ are recommended for any ap- proach to future treatment strategies. The scale is based on rationale of antimicrobial stewardship strategy formulary restrictions, accredited by Ontario public health [20]. Table 4

Table 4. Summary of recommendation for future use of antibiotics against E. coli urinary tract infections based on the current average and trend of resistance, cost and side effects.

\begin{tabular}{|c|c|c|c|c|c|c|c|}
\hline Antibiotic & $\begin{array}{c}\begin{array}{c}\text { Average } \\
\text { resistance }\end{array} \\
\% \\
\end{array}$ & $\begin{array}{l}\text { Overall } \\
\text { trend }\end{array}$ & Cost* & $\begin{array}{l}\text { Extreme adverse } \\
\text { effects [43] }\end{array}$ & Current Role [18] & $\begin{array}{l}\text { Level of } \\
\text { recommendation } \\
\text { for future } \\
\text { protocols** }\end{array}$ & $P$ value \\
\hline Amikacin & 15.2 & + & $(11-20)$ USD & $\begin{array}{l}\text { Neurotoxicity / } \\
\text { Nephrotoxicity / } \\
\text { Ototoxicity }\end{array}$ & $\begin{array}{l}\text { Resistant ESBL } \\
\text { infections }\end{array}$ & B & 0.902 \\
\hline Amoxicillin & 68.5 & - & $(11-20)$ USD & $\begin{array}{c}\text { Diarrhea / Nausea / } \\
\text { Vomiting }\end{array}$ & $\begin{array}{l}\text { First line agent in UTI } \\
\text { in pregnancy }\end{array}$ & C & 0.017 \\
\hline Cefepime & 53.0 & - & $(21-30)$ USD & $\begin{array}{l}\text { Positive coombs test } \\
\text { without hemolysis / } \\
\text { Rash Diarrhea }\end{array}$ & $\begin{array}{c}\text { First line agent in } \\
\text { pregnancy }\end{array}$ & B & 0.004 \\
\hline Cefixime & 44.5 & + & $<10$ USD & $\begin{array}{c}\text { Diarrhea / Fever } \\
\text { / Elevated liver } \\
\text { enzymes /Headache }\end{array}$ & No current role & C & 0.026 \\
\hline Cefotaxime & 65.9 & - & $(11-20)$ USD & $\begin{array}{c}\text { Nephrotoxicity / } \\
\text { Fever / Elevated liver } \\
\text { enzymes / } \\
\text { Pain at the site of } \\
\text { injection }\end{array}$ & No current role & B & 0.004 \\
\hline Cefoxitin & 23.0 & - & $(21-30)$ USD & $\begin{array}{l}\text { GIT upset / Blood } \\
\text { dyscrasias }\end{array}$ & $\begin{array}{l}\text { Second line agent for } \\
\text { cystitis }\end{array}$ & C & 0.001 \\
\hline Ceftazidime & 59.0 & - & $>30$ USD & $\begin{array}{l}\text { Increase in liver } \\
\text { transaminases } \\
\text { / Eosinophilia / } \\
\text { Phlebitis / Immune } \\
\text { hypersensitivity } \\
\text { reactions }\end{array}$ & No current role & B & 0.005 \\
\hline Ceftriaxone & 65.7 & - & $(21-30)$ USD & $\begin{array}{l}\text { Blood dyscrasias } \\
\text { / Elevated liver } \\
\text { enzymes / Diarrhea } \\
\text { / Indurations at the } \\
\text { site of injection }\end{array}$ & $\begin{array}{l}\text { First line agent in } \\
\text { severely ill patients } \\
\text { / Third line agent in } \\
\text { pyelonephritis }\end{array}$ & B & 0.004 \\
\hline Cefuroxime & 47.4 & + & $<10$ USD & $\begin{array}{l}\text { GIT upset / Anemia / } \\
\text { Thrombophlebitis }\end{array}$ & $\begin{array}{l}\text { Second line agent for } \\
\text { cystitis }\end{array}$ & C & 0.452 \\
\hline Ciprofloxacin & 59.1 & - & $<10$ USD & $\begin{array}{l}\text { Nausea / Rash / } \\
\text { Diarrhea }\end{array}$ & $\begin{array}{c}\text { Second line agent for } \\
\text { pyelonephritis }\end{array}$ & B & 0.000 \\
\hline Cotrimoxazole & 57.1 & - & $<10$ USD & $\begin{array}{l}\text { Seizure / Immune } \\
\text { hypersensitivity } \\
\text { reaction / Fulminant } \\
\text { hepatic necrosis }\end{array}$ & $\begin{array}{l}\text { First line agent } \\
\text { for cystitis and } \\
\text { pyelonephritis }\end{array}$ & B & 0.083 \\
\hline
\end{tabular}




\begin{tabular}{|c|c|c|c|c|c|c|c|}
\hline Antibiotic & $\begin{array}{c}\begin{array}{c}\text { Average } \\
\text { resistance }\end{array} \\
\%\end{array}$ & $\begin{array}{l}\text { Overall } \\
\text { trend }\end{array}$ & Cost* & $\begin{array}{l}\text { Extreme adverse } \\
\text { effects [43] }\end{array}$ & Current Role [18] & $\begin{array}{l}\text { Level of } \\
\text { recommendation } \\
\text { for future } \\
\text { protocols** }\end{array}$ & $P$ value \\
\hline Ertapenem & 5.1 & - & $>30$ USD & $\begin{array}{c}\text { GIT upset / } \\
\text { Phlebitis / Fever / } \\
\text { Edema }\end{array}$ & $\begin{array}{l}\text { Severe, complicated } \\
\text { and resistant } \\
\text { pyelonephritis / } \\
\text { ESBL infections }\end{array}$ & B & 0.094 \\
\hline Gentamicin & 22.1 & - & $<10$ USD & $\begin{array}{l}\text { Neurotoxicity / } \\
\text { Nephrotoxicity / } \\
\text { Ototoxicity / Gait } \\
\text { instability / Edema / } \\
\text { Rash / Itching }\end{array}$ & $\begin{array}{l}\text { Second line agent in } \\
\text { severely ill patients }\end{array}$ & C & 0.039 \\
\hline Imipenem & 1.2 & - & $(21-30)$ USD & $\begin{array}{c}\text { Phlebitis / } \\
\text { Eosinophilia / Rash / } \\
\text { Seizure }\end{array}$ & $\begin{array}{l}\text { Severe, complicated } \\
\text { and resistant } \\
\text { pyelonephritis / } \\
\text { ESBL infections }\end{array}$ & A & 0.722 \\
\hline Nalidixic acid & 62.2 & + & $(11-20)$ USD & $\begin{array}{c}\text { Neurological } \\
\text { symptoms / GIT } \\
\text { upset }\end{array}$ & No current role & B & 0.002 \\
\hline Nitrofurantoin & 20.5 & + & $<10$ USD & $\begin{array}{c}\text { Methemoglobinemia } \\
\text { / Arthralgia / Rash / } \\
\text { Vasculitis }\end{array}$ & $\begin{array}{l}\text { First line agent for } \\
\text { cystitis and UTI in } \\
\text { pregnancy }\end{array}$ & C & 0.095 \\
\hline Norfloxacin & 35.5 & - & $<10$ USD & $\begin{array}{l}\text { Tendinitis / } \\
\text { Neurological } \\
\text { symptoms / GIT } \\
\text { upset / Skin }\end{array}$ & No current role & C & 0.816 \\
\hline $\begin{array}{r}* \text { : Cost per } \\
\\
* * \text { lev } \\
\text { favorable f } \\
\text { average resista }\end{array}$ & $\begin{array}{l}\text { igle antibioti } \\
\text { of recomme } \\
\text { ures: } B, \geq 4 f \\
\text { ce of less th }\end{array}$ & $\begin{array}{l}\text { dation: } \\
\text { vorable f } \\
\text { 50\% b }\end{array}$ & $\begin{array}{l}\text { tained by Jo } \\
\text { cale of } 6 \text { poi } \\
\text { ures: C. C co } \\
\text { higher than }\end{array}$ & $\begin{array}{l}\text { University Hospital ph } \\
\text { epresented by the prec } \\
\text { presents our recomme } \\
\text { variance of }<0.05 \text {, }\end{array}$ & $\begin{array}{l}\text { harmacy reports of impo } \\
\text { ceding columns was cons } \\
\text { endations for the near fu } \\
\text { egative trend, cost } \leq \text { (11 } \\
\text { involve major }\end{array}$ & $\begin{array}{l}\text { rted drugs quantities in } \\
\text { (2009-2 } \\
\text { structed: } 2 \text { favorable fig } \\
\text { ture protocols. Favorab } \\
\text {-20) USD, side effects th } \\
\text { ital organs and narrow }\end{array}$ & $\begin{array}{l}\text { he years } \\
\text { 18) (17). } \\
\text { res: A, } 3 \\
\text { figures: } \\
\text { to not } \\
\text { pectrum }\end{array}$ \\
\hline
\end{tabular}

\section{Conclusions}

We are concluded with significance that gentamicin, amoxicillin, cefoxitin and cefixime are the most effective antimicrobials to be considered in the future treatment protocols based on $E$. coli resistance profile. During the years 2016 to 2018, we found that the change in treatment protocols has led to significant reduction in the growing resistance of $E$. coli towards some broad-spectrum antibiotics. This was a major advancement in the project of finding out the ideal strategy in fighting antimicrobial resistance. Due to restrictions against improper prescriptions, misuse and overuse of antibiotics, a nota- ble decline in antimicrobial resistance was achieved with a speed that sometimes exceeded the speed of acquiring this resistance. This study clearly implicates that $E$. coli can easily develop resistance in variable degrees among the same class of antibiotics necessitating protocols of prescribing antibiotics to be directed towards antibiotics individually.

\section{Acknowledgements}

The authors declare that they have no conflicts of interest. 


\section{References}

1. Aslam B, Wang W, Arshad MI, Khurshid M, Muzammil S, Rasool $\mathrm{MH}$, et al. Antibiotic resistance: a rundown of a global crisis. Infect Drug Resist 2018, 11: 1645.

2. Cag Y, Caskurlu H, Fan Y, Cao B, Vahaboglu H. Resistance mechanisms. Ann Translat Med 2016, 4.

3. Li B, Webster TJ. Bacteria antibiotic resistance: New challenges and opportunities for implant-associated orthopedic infections. J Orthop Res 2018, 36: 22-32.

4. Allcock S, Young E, Holmes M, Gurdasani D, Dougan G, Sandhu $\mathrm{M}$, et al. Antimicrobial resistance in human populations: challenges and opportunities. Glob Health Epidemiol Genom 2017; 2: e16

5. Soto SM. Role of efflux pumps in the antibiotic resistance of bacteria embedded in a biofilm. Virulence 2013, 4: 223-9.

6. Lee C-R, Cho IH, Jeong BC, Lee SH. Strategies to minimize antibiotic resistance. Int J Environ Res Public health 2013; 10 : 4274-305.

7. Belyayeva M, Jeong JM. Acute Pyelonephritis. StatPearls: StatPearls Publishing; 2019.

8. Minardi D, d'Anzeo G, Cantoro D, Conti A, Muzzonigro G. Urinary tract infections in women: etiology and treatment options. Int J Gen Med. 2011;4: 333-343

9. Ahmed A-fA-m, Solyman AA-k, Kamal SM. Potential hostrelated risk factors for recurrent urinary tract infection in Saudi women of childbearing age. Int Urogynecol J 2016, 27:1245-53.

10. Klingeberg A, Noll I, Willrich N, Feig M; Emrich D,Zill E et al. Antibiotic-Resistant E. coli in Uncomplicated CommunityAcquired Urinary Tract Infection. Dtsch Arztebl Int. 2018;115(2930):494-500.

11. Flores-Mireles AL, Walker JN, Caparon M, Hultgren SJ. Urinary tract infections: epidemiology, mechanisms of infection and treatment options. Nat Rev Microbiol. 2015; 13(5): 269-284.

12. Schmiemann G, Kniehl E, Gebhardt K, Matejczyk MM, Hummers-Pradier E. The diagnosis of urinary tract infection: a systematic review. Dtsch Arztebl Int 2010; 107(21):361-367.

13. Piątek BMZ. Urinary tract infections of Escherichia coli strains of chaperone-usher system. Polish J Microbiol 2011,60: 279-85.

14. Simmering JE, Tang F, Cavanaugh JE, Polgreen LA, Polgreen $\mathrm{PM}$. The increase in hospitalizations for urinary tract infections and the associated costs in the United States, 1998-2011. Open Forum Infect Dis. 2017; 4(1): ofw281.

15. Al-Badr A, Al-Shaikh G. Recurrent urinary tract infections management in women: a review. Sultan Qaboos Univ Med J 2013; 13(3): 359-367.

16. Nairoukh YR, Mahafzah AM, Irshaid A, Shehabi AA. Molecular Characterization of Multidrug Resistant Uropathogenic E. Coli Isolates from Jordanian Patients. Open Microbiol J 2018, 12: 1-7.

17. Jordan University Hospital Pharmacy Reports of Imported Drugs Quantities. Amman,Jordan: Jordan University Hospital; 20092018.
18. Brusch JL, Bavaro M, Cunha B, Tessier J. Urinary Tract Infection (UTI) and Cystitis (Bladder Infection) in Females Treatment \& Management. Medscape Reference 2019.

19. M100, Performance Standards for Antimicrobial Susceptibility Testing. Clinical and Laboratory Standards Institute. 2017. Available from: https://clsi.org/media/1469/m100s27 sample.pdf.

20. Antimicrobial Stewardship Strategy:Formulary restriction. Ontario Agency for Health Protection and Promotion (Public Health Ontario). 2016. Available from: https://www. publichealthontario.ca/-/media/documents/asp-formularyrestrictions.pdf?la=en.

21. Antimicrobial Stewardship Program strategy criteria reference guide [Internet]. Ontario Agency for Health Protection and Promotion (Public Health Ontario). 2015. Available from: https:// www.publichealthontario.ca/-/media/documents/asp-criteriareference-guide.pdf?la=en.

22. Bajaj P, Singh NS, Virdi JS. Escherichia coli $\beta$-lactamases: what really matters. Front Microbiol 2016, 7: 417.

23. Fasugba O, Gardner A, Mitchell BG, Mnatzaganian G. Ciprofloxacin resistance in community-and hospital-acquired Escherichia coli urinary tract infections: a systematic review and meta-analysis of observational studies. BMC infect Dis 2015 15: 545.

24. National Action Plan to Combat Antimicrobial Resistance Hashimate Kingdom of Jordan, Ministry of Health; 2018.

25. Antimicrobial Resistance : National action plans [Internet]. World Health Organization. 2016. Available from: https://www. who.int/antimicrobial-resistance/national-action-plans/en.

26. Joint Commission International Accreditation Standards for Hospitals. 5th ed. Oakbrook Terrace, Illinois 60181 US: Joint Commission International; 2014.

27.Jordan National Drug Formulary (JNDF). 2nd ed. Jordan: Ministry of Health; 2011.

28. Cho S-Y, Choi S-M, Park SH, Lee D-G, Choi J-H, Yoo J-H. Amikacin therapy for urinary tract infections caused by extended-spectrum $\beta$-lactamase-producing Escherichia coli. Korean J Intern Med 2016, 31: 156-161.

29. Hasvold J, Bradford L, Nelson C, Harrison C, Attar M, Stillwell T. Gentamicin resistance among Escherichia coli strains isolated in neonatal sepsis. Journal of neonatal-perinatal medicine 2013, 6: 173-7.

30. Gregson DB, Matlow AG, Simor AE, Tuffnell PG, Low DE, Feld $\mathrm{R}$, et al. Cotrimoxazole-resistant Escherichia coli bacteremia in neutropenic patients at a regional oncology hospital. Canadian J Infect Dis Med Microbiol 1992;3:14-8.

31. Cunha BA, Schoch PE, Hage JR. Nitrofurantoin: preferred empiric therapy for community-acquired lower urinary tract infections. Mayo Clin Proc 2011, 86: 1243-4; 
32. Leflon-Guibout V, Jurand C, Bonacorsi S, Espinasse F, Guelfi $M C$, Duportail F, et al. Emergence and spread of three clonally related virulent isolates of CTX-M-15-producing Escherichia coli with variable resistance to aminoglycosides and tetracycline in a French geriatric hospital. Antimicrob Agents Chemother 2004, 48: 3736-42.

33. Baroud M, Araj GF, Matar G, Mjtlajo AA. Spread of CTX-M-15 Extended Spectrum $\beta$-lactamases encoding genes among Enterobacteriaceae in the Middle Eastern Region. I A J A A; 2011, 1,1-8.

34. Leigh A. Augmentin (Amoxycillin and Clavulanic Acid) in the Treatment of Urinary Tract Infections. Scottish Med J 1982;27: S28-S34.

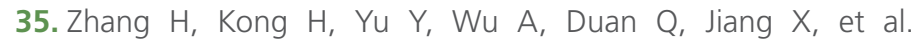
Carbapenem susceptibilities of Gram-negative pathogens in intra-abdominal and urinary tract infections: updated report of SMART 2015 in China. BMC Infect Diseases 2018, 18: 493.

36. Al-Jamei SA, Albsoul AY, Bakri FG, Al-Bakri AG. Extendedspectrum $\beta$-lactamase producing $E$. coli in urinary tract infections: A two-center, cross-sectional study of prevalence, genotypes and risk factors in Amman, Jordan. J Infect Public Health 2019, 12: 21-5.

37. Peri AM, Doi $Y$, Potoski BA, Harris PNA, Paterson DL, Righi E. Antimicrobial treatment challenges in the era of carbapenem resistance. Diagn Microbiol Infect Dis 2019;94: 413-25.

38. Niranjan V, Malini A. Antimicrobial resistance pattern in Escherichia coli causing urinary tract infection among inpatients. Indian J Med Res 2014;139: 945-948.
39. Shakhatreh MAK, Swedan SF, Ma'en A, Khabour OF. Uropathogenic Escherichia coli (UPEC) in Jordan: Prevalence of urovirulence genes and antibiotic resistance. J King Saud UnivSci 2019;31 (4),648-652

40. Chua KY, Stewardson AJ. Individual and community predictors of urinary ceftriaxone-resistant Escherichia coli isolates, Victoria, Australia. Antimicrob Resist Infect Contl 2019, 8: 36.

41. Endimiani A, Perez F, Bonomo RA. Cefepime: a reappraisal in an era of increasing antimicrobial resistance. Expert Rev Anti Infect Ther. 2008;6(6): 805-824.

42. Pourakbari B, Mamishi S, Shokrollahi MR, Heydari H, Mahmoudi S, Banar M, et al. Molecular characteristics and antibiotic resistance profiles of Escherichia coli strains isolated from urinary tract infections in children admitted to children's referral hospital of Qom, Iran. Ann Ig 2019, 31: 252-62.

43. Kapoor A and Raju S. Illustrated medical pharmacology: average resistance. UTI: urinary tract infection. AMR: antimicrobial resistance plans. ESBL: extended spectrum B-lactamase. Medical Publishers (P) Ltd, New Delhi:2013.
Publish in The International Arabic Journal of Antimicrobial Agents

The Journal is an open access peer-reviewed journal that publishes scientific papers about all aspects of antimicrobials. The journal will publish original research articles, reviews, brief reports and case reports dealing with basic and clinical antibacterial agents, antiviral, antiprotozoals, antituberculuous, antifungal and antihelminthes agents. All manuscripts must be prepared in English, and are subject to a rigorous and fair peer-review process. Accepted papers will immediately appear online. The journal aims to advance the knowledge, attitude and the research of chemotherapy in the Arabic world in cooperation with international, national scientific and public societies as well as research centers with similar aims and objectives. 